\title{
Goce sin límites: manifestaciones misóginas en canciones de reggaetón
}

Limitless Enjoyment: misogynous manifestations in reggaetón songs

\author{
Alondra Alpízar-Lorenzo ${ }^{a}$, Lorena Hernández-Muñoz ${ }^{b}$, María C. Ledezma-Trujillo ${ }^{c}$, Marco A. \\ Linares-Villa ${ }^{d}$, Lizbeth Rodríguez-Cortés ${ }^{e}$, Gelacio Guzmán-Díaz ${ }^{f}$, Jesús Cisneros-Herrera ${ }^{g}$
}

\begin{abstract}
:
The aim of this qualitative study was to analyze the violent, sexual, misogynous and hateful content.in reggaetón songs, as well as its relation to limitless enjoyment from a psychoanalytic point of view. For that purpose, 50 reggaetón song lyrics were selected, 20 sung by female singers and 30 sung by male singers. Atlas.ti, a program for analyzing qualitative data was used. Five categories were determined, for example, woman reification, hateful feelings, love feelings and male perception of female figure. In results, it is highlighted the presence of phrases about woman reification and women being perceived as submissive, which oppose to men being perceived as dominant in most of analyzed lyrics. At the end, it is discussed the influence that these kinds of songs might exert over public, pushing them to look for a limitless enjoyment, which may carry them to present behaviors risky for themselves and for their environment.
\end{abstract}

\section{Keywords:}

Misogyny, Violence, Limitless enjoyment, content analysis, Reggaetón

\section{Resumen:}

El propósito de este estudio cualitativo fue analizar el contenido violento, sexual, misógino y de odio en canciones de reggaetón y su relación con el término psicoanalítico goce sin límites. Para ello, se seleccionaron 50 letras de canciones de reggaetón, 20 con intérpretes femeninos y 30 con intérpretes masculinos, y utilizando el programa de análisis de datos cualitativos Atlas.ti se identificaron categorías como: cosificación de la mujer, sentimientos de odio, sentimientos de amor, percepción masculina de la figura femenina, entre otras, mismas que permitieron identificar el contenido requerido. En los resultados se destacada la presencia de frases de cosificación y percepción sumisa de la mujer en contraste con una percepción dominante de los hombres en la mayoría de las letras analizadas. Finalmente se discute la influencia que estas canciones pueden tener sobre los escuchas, orientándolos a un goce sin límites que puede derivar en conductas de riego para ellos mismos y su entorno.

\section{Palabras Clave:}

Misoginia, Violencia, Goce sin límites, Análisis de contenido, Reggaetón

\section{Introducción}

A lo largo de la historia, numerosas teorías sobre la música tanto filosóficas, teológicas, sociológicas o políticas, han compartido la convicción de que la música mueve o influye notoriamente a quienes la escuchan, en un sentido ético o moral. La música se presenta como un lenguaje organizado, un componente cultural y un generador de emociones, encontrando que los ritmos rápidos y con mayor tonalidad producen estados de felicidad, por el contrario, la música más lenta y con menor tonalidad suele producir sentimientos de tristeza $(1,2)$. Incluso desde la antigüedad hay principios hedónicos que llevan implícitos los gustos y placeres musicales de los

\footnotetext{
aAutor de Correspondencia, Universidad Autónoma del Estado de Hidalgo, https://orcid.org/0000-0002-0925-4889, Email: al357558@uaeh.edu.mx

b Universidad Autónoma del Estado de Hidalgo, https://orcid.org/0000-0001-5395-5714, Email: he358900@uaeh.edu.mx

c Universidad Autónoma del Estado de Hidalgo, https://orcid.org/0000-0002-4626-7793, Email: le362766@uaeh.edu.mx

${ }^{d}$ Universidad Autónoma del Estado de Hidalgo, https://orcid.org/0000-0002-8952-7460, Email: li355647@uaeh.edu.mx

Eniversidad Autónoma del Estado de Hidalgo, https://orcid.org/0000-0002-2301-1023, Email: ro303182@uaeh.edu.mx

${ }^{\mathrm{f}}$ Universidad Autónoma del Estado de Hidalgo, https://orcid.org/0000-0003-4869-8658, Email: gelacio_guzman@uaeh.edu.mx

g Universidad Autónoma del Estado de Hidalgo, https://orcid.org/0000-0003-1370-8086, Email: jesus_cisneros@uaeh.edu.mx
} 
receptores masificados, la sensualidad, las emociones de base, el cuerpo humano, las salas de baile, las discotecas e incluso la sublimación ética liberada por medio ciertos ritmos que llevan a la liberación de energía sexual (1). Charles Darwin propuso en la publicación el origen del hombre que al igual que el canto de los pájaros, el objetivo principal de la música es el sexo, en otras palabras, fue de los ancestros masculinos y femeninos de la humanidad que se heredó el propósito de cultivar al sexo opuesto mediante el canto (3).

Por su parte lo simbólico corresponde a un conjunto de significados atribuidos a una representación. Los sistemas simbólicos son instrumentos de comunicación y de dominación que dan lugar a la aprobación mutua entre lo lógico y lo moral. Simultáneamente se reproduce el orden social y se impone una visión del mundo, en la cual el poder simbólico requiere de un acuerdo entre los dominantes y los dominados (4).

La violencia simbólica es esa violencia que arranca sumisiones que ni siquiera se perciben como tales apoyándose en unas "expectativas colectivas", en unas creencias socialmente inculcadas (5).

En concordancia con lo anterior, la violencia simbólica dirigida a la mujer se hace presente en la cotidianidad por medio de la representación de la mujer y de todo lo considerado femenino. Por ejemplo, se le asignan labores que son menospreciadas, como el cuidado de la casa, y se le atribuyen rasgos que tienen una valoración negativa, como debilidad, la emotividad y la irracionalidad. Las múltiples formas de violencia simbólica se han hecho presentes de diversas maneras y en diferentes espacios, y una de las formas de manifestación está en el lenguaje (6).

En la sociedad, las relaciones comunicativas son siempre relaciones de poder. La comunicación tiene un papel fundamental; por medio de ella se nos permite conocer y comprender. Las relaciones interpersonales que constituyen a la sociedad, se asocian a ellas mediante el poder, donde la persona cuenta con la capacidad relacional que le permite ser un actor social que logra influir de forma asimétrica en las decisiones de otras personas sociales de modo que favorezca su voluntad, sus intereses, y valores de la persona que tiene el poder. La manera en que son utilizados el poder y la violencia simbólica acaba por ser invisible y dulce. La violencia simbólica no es otro tipo de violencia, sino más bien, es un conjunto de actitudes, gestos, creencias, y patrones de conducta que nos permiten ver que existe la opresión, discriminación y subordinación en un contexto. Se encuentra presente en todas las clases de violencia como psicológica, económica, física, y sexual. Estas actitudes se vuelven tan cotidianas que se normalizan y llegan a ser tomadas como un gesto de afectividad $(7,5,8)$.
En algunos de sus mensajes, la comunicación lleva implícito el mandato "debes gozar", que incluso se interpreta como "siempre hace falta algo más", lo cual provoca la experiencia de un vacío que se intenta llenar con sexo, fiestas, gimnasio, etc. Otro aspecto importante en el hombre de la modernidad, es que el empuje al goce sin límites puede llevar al sujeto a perderse a sí mismo, ya que se pueden realizar conductas de riesgo por placeres excesivos (9).

Los tipos de violencia que se presentan en las letras de estas canciones, han ido modificándose a lo largo del tiempo, aunque parecieran tener una tendencia. Los tipos de violencia de género que implican dominación a través de la fuerza han perdido relevancia, para practicar otro tipo de violencia de género que implica formas de dominación más sutiles, como la violencia simbólica y la violencia psicológica, que han tomado más fuerza (10).

Lo que entendemos por violencia de género y cómo lo valoramos tiene que ver con el marco del discurso social y cultural. La violencia de género surge a partir del discurso social y cultural. El contexto social es un factor fundamental en el desarrollo del ser humano, a partir de ahí adquiere valores, conductas y costumbres que va transmitiendo a lo largo de su vida. La música es el reflejo del contexto social en el cual es creada y alude a las personas que comparten este entorno. Por ello, es una forma de acceder a la visión de la realidad de un grupo y del conocimiento de su vida (11)

Una de las consecuencias que puede tener el sexismo benévolo es la sexualización. La sexualización de la mujer ocurre cuando ésta es tratada como objeto sexual y evaluada en función de sus características físicas. En este tipo de sexismo, en donde la mujer se visualiza como objeto de placer sexual y no como ser humano, es comúnmente reproducido en el reggaetón. Gill afirma que numerosos estudios apoyan la idea de que la sexualización es una forma de controlar a las mujeres (12, 13).

Cuando se pretende poseer al otro por completo, se elimina su condición humana, para convertirse en objeto de consumo estereotipado, disminuyendo el valor de la persona y violentando la integridad física en su totalidad. Cuando el objeto de deseo no es visto ya como otro ser humano, sino como una cosa, se elimina así la posibilidad de que nuestro deseo sea juzgado por él (14).

La música es un reflejo del contexto social, la cultura, el bagaje histórico e incluso un medio catártico. En el reggaetón hay uso de objetos y/o frutas para referirse a los genitales femeninos clasificándolos y tomándose como objeto de placer (15).

La música es utilizada como una manera de expresión cultural, emocional y social. Por medio de ella se refleja el cómo se observa y se entiende al mundo subjetivamente. Cada persona escucha el tipo de música de acuerdo a la 
ideología que tiene y a las experiencias que ha vivido. Cada persona, por medio de la música, manifiesta sus deseos, emociones y necesidades que le surgen y lo comparte abiertamente con aquellas personas que lo rodean (16).

El reggaetón empieza a ser un ritmo popularmente aceptado y difundido por los medios a partir del año 2000. Galluci señala que, antes del 2000 , el reggaetón era un ritmo clandestino $y$, aunque en realidad no existe consenso pleno en cuanto al origen de este género musical, suele afirmarse que surgió del intercambio cultural y musical que tuvo lugar en los años ochenta entre Panamá, Puerto Rico y República Dominicana (17).

El reggaetón les dio a los latinos una voz, una historia (musical) y una identidad, por lo que tiene dimensiones sexistas que han sido heredadas del hip hop. En este sentido, el significante del latino se ha visto denigrado por un conjunto de estrategias de marketing sin sentido que lo único que han generado es misoginia y falsas especulaciones de humillación hacia los cantautores que, sin un poco de responsabilidad, han decidido ser partícipes del boicot al género reguetonero (18).

El discurso del reggaetón se vuelve lenguaje y práctica. Sus representaciones de las prácticas sociales y el poder (masculino) producen una fuente de conocimiento social. Estas canciones refuerzan la estructura del patriarcado, que representa el poder del hombre heterosexual a través de letras que evidencian prácticas sexuales basadas en jerarquías de género (19).

Comunica a sus oyentes contenidos que incitan a un libertinaje sexual y a una cosificación y discriminación de la mujer. Lo que causó que dicho género musical haya sido rechazado y desacreditado por la sociedad y que, detrás de su aparente modernidad, sea un género popular que promueve conductas prodemocráticas y premodernas (20).

Podemos mencionar que este ritmo, en relación con el resto de la música, da un salto en cuanto al desarrollo histórico del tema de la sexualidad, porque se hace de forma explícita. Cuando anteriormente se veía que en la música no se mostraba contenido sexual, ahora vemos que se hace sin prohibiciones, y las personas que escuchan este género la han aceptado sin ningún problema; ha logrado que se vea de una manera tan normalizada y aceptada (6).

Un estudio realizado por Cerbino, Chiriboga, y Tutevén nos deja ver que escuchar música es la actividad que más disfrutan realizar los jóvenes durante sus tiempos libres. Asimismo, se identificó que la letra es el elemento de las canciones que mayor goce proporciona, por encima del ritmo, pues ésta cumple una función de acompañamiento y/o modulación de los estados de ánimo (21).

Tras un análisis morfológico, lingüístico y semiótico, Urdaneta concluye que la mujer, dentro del reggaetón, es considerada como un instrumento sexual, además de ser comparada con animales (gata, cachorrita). Asimismo, pone de manifiesto que promueve la pérdida de valores morales, incita a una sexualidad promiscua e irresponsable, y alude a la violencia en contra de la mujer (14).

En un estudio realizado por Penagos, cuyo objetivo fue comprender de qué manera influye la música reggaetón en el estilo de vida de los estudiantes, se concluyó que el reggaetón puede exaltar la sexualidad de los adolescentes y disminuir sus barreras morales o hacerlas desaparecer. El adolescente orientado por este tipo de discurso musical puede crear su propia ética y moral, de modo subjetivo a su acomodo y gusto. Esto no solo apoya la idea de que el reggaetón incita al goce sin límites, también sugiere que, además de ser un reflejo de la sociedad, el reggaetón es capaz de impactar en ella (22, 9).

Un análisis lingüístico realizado por Urdaneta indicó que los temas más recurrentes en las canciones de reggaetón son las relaciones bruscas, la zoofilia y el sadomasoquismo. Esto se concluyó a partir de la identificación de lexías tales como pobre diabla y gata, utilizadas para referirse a la mujer; perro, gato y pobre diablo, para referirse al hombre; y palabras como perreo, comer, morder, clavar, y dar candela, para referirse a acciones efectuadas de los sujetos, lo cual remite a fantasías orales primitivas que implican la destrucción o el daño al objeto de deseo. Asimismo, tales expresiones pueden catalogarse también dentro del goce sin límites $(23,9)$.

En el reggaetón, la sexualidad se presenta como una relación social de dominación entre el hombre activo que exige y la mujer pasiva que acepta las condiciones, y que naturaliza, a su vez, el uso de la violencia. Una vez más, podemos ver que el mensaje a través del reggaetón responde a lógicas de dominación propias del sistema patriarcal, al promover un orden de dominación por género que deja en una posición de desigualdad a la mujer. Asimismo, esta perspectiva se relaciona con la cosificación de la mujer como un objeto de goce y con la hipersexualización de la misma $(14,24)$.

A través de referencias líricas, imágenes, perreo, dembow y varios otros elementos que se plasman de forma exótica para la expresión ambiental de identidad, se puede notar claramente la manipulación de los medios encargados de su difusión, y, además, ha sido esquematizada de una forma burda y grotesca para su comercialización, que nada tiene que ver con su origen que más bien intentaba darle al puertorriqueño y posteriormente al latino una forma de identificación cultural (25).

Carballo hace un análisis sobre sobre la identidad masculina presente en las canciones y videos musicales pertenecientes al género reggaetón. Se encontraron tres 
contenidos discursivos recurrentes: mujeres y sexo, violencia, e identidad (representación del bienestar material). Se infiere que estos tres componentes de la identidad masculina están altamente influenciados por la cultura patriarcal presente en la sociedad latinoamericana. De igual manera, podemos relacionar las relaciones sexuales con mujeres y el uso de los bienes materiales como una incitación al goce sin límites $(16,15,9)$.

Las mujeres que participan en coreografías se visten de forma sexy y con muy poca ropa: faldas reveladoras, pantalones cortos y los escotes son indispensables. De igual manera, poseen una anatomía que en conjunto con el vestuario son característicos del estereotipo sexual. Para Díaz, el mostrar de manera explícita la diferencia de géneros por medio de imágenes como se observa en los videos musicales, refuerza la violencia hacia la mujer (17, 24).

El discurso que se muestra en las canciones de reggaetón se relaciona principalmente con la mujer. Lo que aquí se trasmite a las personas que lo escuchan es contenido sexual y violento, se da mayor valor a los atributos físicos y sexuales que ellas tienen. Estos atributos se resaltan más que cualquier otro y tienen que cumplir los estereotipos que la sociedad estipula para la satisfacción principalmente de los hombres (26).

Díaz menciona que el discurso del reggaetón promueve conductas sexistas y la cosificación de la mujer; el consumo de este género está relacionado con el alcohol, la hipersexualidad y los medios de comunicación. Asimismo, Penagos escribe que el contenido que comparten estas canciones promueve la pérdida de los valores morales y personales, la trasgresión de códigos sociales, incitan al sexo y convierten a la mujer en un instrumento sexual $(24,22)$.

Históricamente ha existido un predominio masculino en el escenario musical latinoamericano, lugar donde, por cierto, la cultura patriarcal se encuentra fuertemente presente. Si se toma en cuenta que la música es un reflejo del contexto sociocultural en que se desarrolla, se vuelve inevitable que las canciones llevan inmersos mensajes violentos y sexistas que pueden llegar a pasar desapercibidos $(6,15,10)$.

En la actualidad hay pérdida de habilidades para acercarse a otros, lo que ocasiona que las formas de expresión del deseo al goce puedan llegar a ser obscenas para el receptor, debido a que los lazos suelen ser superficiales e incluso puede haber confusión entre los límites entre lo público y lo privado (9).

Piedad considera que cada individuo es un artista que interpreta su habilidad, virtud por la cual las culturas se reflejan en su entorno natural o artificial. Es decir, la cultura se ha modificado y ha dejado de ser aristocrática, para comenzar a ser más una pluralidad al alcance de todos y que, además, se ha complementado con un conjunto de altisonantes destellos de folklore en donde, para gusto de todos, se plasman las vivencias urbanas (27).

El objetivo principal de este estudio, es identificar el contenido sexual, dentro de las canciones de reggaetón, que incita al goce sin límites. Esto a través de la comparación de ocho categorías de análisis explicadas más adelante.

\section{Método}

El presente estudio es de tipo cualitativo descriptivo.

\section{Materiales}

Se utilizó un muestreo no probabilístico intencional, mediante el cual se seleccionaron 50 canciones de reggaetón. Se tomó como criterio de inclusión el contenido sexual explícito. Estas canciones, a su vez, se dividieron en dos submuestras, para lo que se tomó como criterio el sexo del intérprete (masculino, $n=30$; femenino, $n=20$ ).

\section{Análisis de contenido}

Las letras de las canciones fueron transcritas y codificadas utilizando el programa informático ATLAS.ti. La codificación consta de ocho categorías:

1. Cosificación de la mujer. Hace referencia a al uso de una mujer para eliminar su valor como ser humano. La manera en la que más se presenta la cosificación de la mujer es la sexual, en donde se vuelve en un objeto a disposición del hombre.

1.1 Reconocimiento como persona: Reconocimiento como mujer y no como objeto sexual.

2. Vinculación afectiva o sentimientos: El apego o vinculación afectiva se desarrolla con una persona cercana, especial, que persiste en el tiempo, y hace que se busque la cercanía con esa persona y que es fácilmente observable.

2.1 Sentimientos de odio: Repulsión hacia algo o alguien expresado por medio del reggaetón.

2.2 Sentimientos de amor. Vivo afecto hacia algo o alguien expresado por medio del reggaetón.

3. Autopercepción femenina en el reggaetón: Manera en que las intérpretes de reggaetón suelen verse a sí mismas, estereotipos y sobrenombres ofensivos.

3.1 Autodenominación animal: las intérpretes hacen uso de sobrenombres de animales para referirse a sí mismas. 3.2 Autodenominación humana: se emplean apelativos característicos para referirse entre humanos.

3.3 Autopercepción dominante: visión de sí mismas como mandante.

4. Percepción masculina de la figura femenina en el reggaetón: Manera en que nombran y hacen referencia a las mujeres los intérpretes masculinos del reggaetón. 
4.1 Percepción sexual masculina de la figura femenina: consiste en la visualización de la mujer como objeto sexual.

4.2 Denominación humana: Se emplean apelativos característicos para referirse entre humanos.

4.3 Percepción masculina de la figura femenina como dominante: Los hombres ven a la mujer como mandante.

5. Autopercepción masculina en el reggaetón: Manera en que los cantantes de reggaetón suelen verse a sí mismos, estereotipos y sobrenombres de superioridad o autoridad. 5.1. Autopercepción masculina dominante: Sexualmente activo, siempre dispuesto, habilidoso, poderoso y deseado, castigador, violento, maleante, adinerado.

5.2. Autopercepción masculina sumisa: El hombre se vuelve objeto de placer de la mujer abusadora.

6. Percepción femenina de la figura masculina en el reggaetón: Manera en que nombran y hacen referencia a los hombres las intérpretes femeninas del reggaetón.

6.1. Percepción dominante: Se concibe al hombre como figura de autoridad, violento, mujeriego, sexualmente poderoso, etc.

6.2. Percepción sumisa: El hombre se percibe como alguien a merced de la mujer controladora y dominante.

7. Anulación de los límites del acceso al placer en mujeres: La mujer centra todos sus recursos en generar situaciones que le generan placer.

7.1 De forma explícita por parte de mujeres: La mujer expresa de forma directa y tácita ya sea su deseo de obtener placer, como fue que lo obtuvo o cuáles son los métodos que puede emplear para obtenerlo.

7.2 Insinuaciones indirectas por parte de mujeres: La mujer hace uso de mensajes subliminales para transmitir su deseos, peticiones y actitudes volcadas hacia la búsqueda de placer.

8. Anulación de los límites del acceso al placer en hombres: El hombre centra todos sus recursos en generar situaciones que le generen placer.

8.1 De forma explícita por parte de hombres: El hombre expresa de forma directa y tácita ya sea su deseo de obtener placer, como fue que lo obtuvo o cuáles son los métodos que puede emplear para obtenerlo.

8.2 Insinuaciones indirectas por parte de hombres: El hombre hace uso de mensajes subliminales para transmitir sus deseos, peticiones y actitudes volcadas hacia la búsqueda de placer a diferencia de las mujeres es mayormente probable que el hombre utilice el "albur" de igual forma.

Una vez hecha la codificación, se realizó un conteo de las veces que cierto código se hizo presente a lo largo de las canciones.

\section{Resultados}

La categoría de Cosificación de la mujer se presenta 71 veces ("eso es mío, no lo pongas a la venta", "Señor oficial, yo la puse a gritar, no hizo nada malo, pero la tuve que castigar") dentro de las 50 canciones $(100 \%, \mathrm{~m}=$ 1.42), lo que muestra la sexualización dentro de este género musical hacia las mujeres. Para poder comparar los resultados de esta categoría, se generó la subcategoría Reconocimiento como persona, sin embargo, no se presenta a lo largo de las canciones, lo que representa un dominio del $100 \%$ en la categoría cosificación de la mujer. Al hacer el conteo por género, en las mujeres se obtuvo una frecuencia de 27 (38.02\%, m= 1.35), mientras que con los hombres se presentó 44 veces $(61.97 \%, m=1.46)$.

Con el objetivo de contrastar resultados, la categoría Percepción del hombre por parte de las mujeres fue dividida en dos subcategorías: Percepción dominante y Percepción sumisa. En cuanto a la primera subcategoría, ésta se hizo presente 40 veces ("Dale bien duro, papi. Papi azotame", "Mamá me dijo que tú eras un mujeriego, que fuera precavida y no jugará con fuego") a lo largo de las 20 canciones interpretadas por mujeres $(80 \%, m=2)$; mientras que la segunda aparece 10 veces ("Tratas de mantenerte en el juego y te dejo seguir. Aún no tienes claro que soy la que controla", "Si tú te portas bien, yo te lo voy a dar como nunca te lo han dado") lo que representa un $20 \%$ y una media igual a 0.5 .

Para la categoría Autopercepción masculina, de igual manera se realizó una división: Autopercepción masculina dominante y Autopercepción masculina sumisa. La primera subcategoría obtuvo una frecuencia igual a 57 ("Si pa' luego es tarde, mami, pues 'tate tranquila si no quieres que te pille duro en una esquina", "No vas a revelarte conmigo o te doy tu castigo. No me hagas abusar de la ley, que comienzo contigo y te acuso de violar la ley. Si sigues en esa actitud voy a violarte, hey") a lo largo de las 30 canciones interpretadas por hombres $(95 \%, m=1.9)$; mientras que la segunda categoría tuvo una frecuencia igual a 3 (“Tú abusas, me usas", "Me robó, pa' su casa me invitó. De repente me jaló y pa'l cuarto me llevó"), lo que representa un $5 \%$ y una media igual a 0.1 .

En la categoría de Análisis de Autopercepción femenina en el reggaetón, se presenta un puntaje de frecuencia igual a 21 ("Dame una noche loca que esta gata no perdona, si te lambes y me tocas, vas a probar esta potra", "Atención todas las chicas góticas, que solo salen de noche y somos gárgolas, que a gatos celosos somos fóbicas, pero en la intimidad somos biónicas") ( $m=1.5)$. Cabe mencionar que, dentro de esta categoría, se plantean tres subcategorías, la primera es Autodenominación animal, que presenta una frecuencia de 13 veces $(m=0.65)$ y que en concordancia al $100 \%$ de la categoría, esta subcategoría presenta $61.9 \%$ del total del porcentaje ("Esta gata se convierte en fiera"," Las 
gatas sueltas"). La segunda subcategoría es Autodenominación humana, con un número de frecuencia igual a $3(\mathrm{~m}=0.15)$ y un porcentaje del $14.2 \%$ ("A mí me gusta que me traten como dama"," Rozando suave va tu mami"). La tercera subcategoría es Autopercepción dominante con una frecuencia de $5(m=0.25)$ y un porcentaje de $23.8 \%$ que corresponde al cien por ciento de la categoría ("Esta gata se convierte en fiera $Y$ no por eso soy una cualquiera"," A ella nadie se le monta Me llaman la atrevida, la potra, la domadora"). De acuerdo con los resultados encontrados, la subcategoría con mayor índice es la primera, y muestra que predominan palabras de animales para hacer referencia a sí mismas y, por medio de éstas, se pone de relieve lo pulsional o lo animal. Cabe mencionar que una característica principal en los animales es actuar de forma inmediata a los impulsos sin inhibiciones culturales. Otro aspecto relevante es que se le da una connotación positiva a esta característica, contrario a lo que sucedía en épocas pasadas, donde se censuraba la actuación inmediata a los impulsos, principalmente en las mujeres.

Por su parte en la categoría de Percepción masculina de la figura femenina en el reggaetón, existe un puntaje de frecuencia igual a $25(\mathrm{~m}=0.83)$, que equivale al $100 \%$ de la suma de la totalidad de las 3 subcategorías que corresponden a ésta ("eres una descara'"."nena"). La primer subcategoría es denominada Percepción sexual masculina de la figura femenina y se hace presente con una frecuencia igual a $4(\mathrm{~m}=0.13)$ que representa un $16 \%$ del porcentaje total ("Ponte encima de mí bellaquita", " Esa nena cuando baila me vuelve loco"), en la segunda subcategoría se plantea la Denominación humana con 15 veces de frecuencia $(m=0.53)$ y un porcentaje igual a $64 \%$ ("mami","bebé"), y por último, Percepción masculina de la figura femenina como dominante con 5 repeticiones $(\mathrm{m}=0.16)$ y un porcentaje equivalente a $20 \%$ ("No te pongas alsadita","baby, es un arma"). Los datos encontrados en la categoría hacen una revelación referente a la percepción de los hombres hacia las mujeres como humanas ya que la subcategoría es la que mayor porcentaje, promedio y frecuencia tiene, haciendo de lado la percepción de ellas como figuras dominantes y la denominación sexual. Cabe mencionar que lo encontrado referente a ésta categoría es escaso.

La categoría Vinculación afectiva o sentimientos se hace presente en 10 ocasiones ("Los días ya no serán grises a tu lado, mi amor, y el destino se hará cargo lo que será la unión, tú y yo, yo y tú unidos por el amor, tú y yo, yo y tú unidos por el amor", "déjame sentir tu piel, déjame probar tus besos déjame sentir que el cielo está cerca de los dos") dentro de las 50 canciones $(m=0.2)$. Para poder realizar una comparación, se hicieron dos subcategorías: Amor y Odio, en donde Amor se presenta 10 ocasiones y Odio en ninguna. Al realizar el conteo por género, se encontró una media igual a 0.3 en mujeres y una de 0.7 en hombres. Con esto se puede observar que su presencia es mayor en las canciones interpretadas por hombres. Podemos notar que su aparición no es significativa. Las canciones de reggaetón muestran que la vinculación afectiva o sentimientos no es esencial para este género, ya que las emociones que se manifiestan son solo para la satisfacción del momento.

La categoría Anulación de los límites del acceso al placer en mujeres tiene un puntaje de frecuencia de $108(m=5.4)$ y equivale a un $100 \%$ de sus dos subcategorías. De forma explícita por parte de mujeres tiene un total de $46(\mathrm{~m}=2.3)$ que equivale a $42.5 \%$, mientras que las Insinuaciones indirectas por parte de mujeres tienen una frecuencia de $62(m=3.1)$ y un porcentaje de $57.4 \%$. De acuerdo con los puntajes que presentan las subcategorías, existe mayormente insinuaciones indirectas que hacen referencia a la búsqueda de placer sin límites, esto muestra que en la actualidad aún existen filtros en la expresión femenina, sin embargo es importante resaltar que según los resultados de este análisis es más fácil para las mujeres expresar de forma directa su deseo de obtener placer, como fue que lo obtuvo o cuáles son los métodos que puede emplear para obtenerlo esto en un comparativo con el género masculino y tratándose de un género musical como el reggaetón.

Asimismo, la categoría de Anulación de los límites del acceso al placer en hombres presenta un puntaje de frecuencia de $152(m=5,0)$ y al $100 \%$ de la suma de sus subcategorías; De forma explícita por parte de hombres con un total de $60(\mathrm{~m}=2)$ que corresponde a $39.4 \%$ e insinuaciones indirectas por parte de hombres con un total de $92(m=3.0)$ y $60.5 \%$ (Dichas categorías fueron tomadas en cuenta con base a formas indirectas de la mención a la búsqueda de placer sin límites: "Baby, hoy no vamo' a dormir (uh-uh-uh). Qué no traje pijama” la mención explícita de dicha búsqueda: "No pares, dale, papi. Bésame, tócame. Dale bien duro, papi"). De acuerdo con los resultados presentados se puede llegar a la conclusión de que en hombres existe una mayor predisposición a la expresión de forma indirecta de situaciones relacionadas con la anulación de los límites del acceso al placer esto en un comparativo con el género femenino al menos en las canciones de reggaetón, esto puede ser mediante mensajes subliminales o la pretensión de forma indirecta, concluimos con la idea de que el hombre suele recurrir más a medios subliminales para la expresión de sus deseos.

\section{Discusión}

Lo socialmente esperado es que se lleve a cabo lo que Bourdieu (28) denomina el principio de división fundamental entre lo masculino, activo, y lo femenino, 
pasivo, y ese principio crea, organiza, expresa y dirige el deseo, el deseo masculino como deseo de posesión, como dominación erótica, y el deseo femenino como deseo de la dominación masculina, como subordinación erotizada. Sin embargo, en el contenido sexual existente en el reggaetón hay indicadores de una pérdida moral que permite una reacción inmediata al instinto por parte de las mujeres. "A los que puedan objetar que muchas mujeres han roto actualmente con las normas y las formalidades tradicionales del pudor y verían en el espacio que dejan a la exhibición controlada del cuerpo un indicio de «liberación»" (Bourdieu, 2000, p. 44) (28).

Otro resultado importante que se nota dentro de las letras de estas canciones, específicamente las interpretadas por mujeres, es la eliminación de su valor como seres humanos, la cosificación es encontrada tanto en hombres como mujeres, sin embargo, el valor que se otorgan a sí mismas llega a ser nulo. Lo que socialmente podemos ver en relaciones de noviazgo o matrimonios, en donde la mujer permite que el hombre tome su cuerpo (que se convierte en un objeto) y lo use para obtener placer.

La popularidad de este género musical ha ido incrementando, las redes sociales y medios de difusión musical como las plataformas de Youtube, Spotify, Amazon Music y muchas otras más ayudan a la difusión de estas canciones, sus seguidores son principalmente personas jóvenes y adolescentes, que debido al mensaje implícito al goce sin límites normalizado en el contenido de las canciones, los lleva como consecuencia a experimentar riesgos innecesarios que los podría llevar a perderse a sí mismos mediante la reproducción de conductas autodestructivas o fuera de lo normalmente aceptado implicando la pérdida de la paz social.

En cuanto a la autopercepción del hombre dentro del reggaetón, encontramos que éste, en la gran mayoría de las canciones, se ve a sí mismo como una persona violenta y dominante, tanto física como sexualmente. Frases como "Si pa' luego es tarde, mami, pues 'tate tranquila si no quieres que te pille duro en una esquina" o "No vas a revelarte conmigo o te doy tu castigo. No me hagas abusar de la ley, que comienzo contigo y te acuso de violar la ley. Si sigues en esa actitud voy a violarte, hey", no sólo crean en el oyente una imagen de hombre dominante, que coincide con prácticas e ideales machistas, sino que incitan a cometer actos delictivos (claramente movidos por la idea del goce sin límites) como la violación sexual.

\section{Referencias}

[1] Riethmüller, A. (2015) Música más allá de la ética, Revista de Estudios Culturales, 18 (2)

[2] Lozano, O., Santos, S y García, F. (2013). El cerebro y la música. Recuperado https://www.uv.mx/rm/num_anteriores/revmedica_vol13_num1/articul os/el_cerebro.pdf

[3] Darwin, C. (2019) Capítulo II. Facultades mentales del hombre y de los animales inferiores, E. Robsy (Ed.), El Origen del Hombre (pp.30), España: Biblioteca digital abierta. Recueperado de http://www.textos.info

[4] Fernández, J. (2005) La noción de violencia simbólica en la obra de Pierre Bourdieu: una aproximación crítica. Madrid. Cuadernos de Trabajo Social Vol. 18 (2005): 7-31

[5] Bourdieu, P. (2000). La dominación masculina. Barcelona: Anagrama.

[6] Carballo, P. (2006) Música y violencia simbólica. Revista de la Facultad de Trabajo Social, 22(22), 28-43.

[7] Bernárdez, A. (2015) Mujeres enmedio(s). Propuestas para analizar la comunicación masiva con perspectiva de género. Madrid: Fundamentos.

[8] De Andrés, S. (2012). Violencia simbólica de género en la publicidad. In J. García Marín y B. Gómez (eds). Diálogos en la cultura de la paridad. Reflexiones sobre feminismo, socialización y poder. (133-146). Santiago de Compostela: USC.

[9] Assef, J. (2013). La subjetividad hipermoderna. Una lectura de la época desde el cine, la semiótica y el psicoanálisis. Buenos Aires: Grama Ediciones.

[10] Arévalo, K., Chellew, E., Figueroa-Cofré, I., Arancibia, A., y Schmied, S. (2018). Ni pobre diabla ni Candy: Violencia de Género en el reggaetón. Revista de Sociología, 33(1), 7-23. Doi:10.535/0719529X.2018.51797

[11] Zurbano, B y Liberia, I. (2014). Revisión teórico-conceptual de la violencia de género y de su representación en el discurso mediático. Una propuesta de resignificación. ZER Revista de Estudios de Comunicación, 36. 121-143.

[12] APA. (2007). Informe del grupo de trabajo de la APA sobre la sexualización de las niñas. Asociación Americana de Psicología. Recuperado de: https://www.apa.org/pi/women/programs/girls/reportfull.pdf

[13] Gill, R. (2008). Empowerment/sexism: Figuring female sexual agency in contemporary advertising. Feminism and Psychology, 18, 35-60.

[14] Marzano, M. (2006). La pornografía y el agotamiento del deseo. Buenos Aires, Argentina: Manantial.

[15] Urdaneta, M. (2007). El reggaetón, entre el amor y el sexo. Análisis semiolingüístico. Trabajo de grado no publicado. Maracaibo: Universidad del Zulia.

[16] Carballo, P. (2007). Reggaetón e identidad masculina. Intercambio, 3(4), 87-101.

[17] Gallucci, M. J (2008). Análisis de la imagen de la mujer en el discurso de reggaetón. Opción, 24(55), 84-100.

[18] Rivera, R., Marshall, W. \& Pacini, D. (2009). Book Review: Reggaeton. Transforming Cultures eJournal, 4(1), 265-268.

[19] Rodríguez, C. (2012). Reggaetón, mujeres e identidades: Yo quiero bailar... eso no quiere decir que pa'la cama voy (Tesis de Maestría, FLACSO Quito). $\quad$ Recuperada de http://repositorio.flacsoandes.edu.ec/handle/10469/5396

[20] Martínez, D. A. (2013). Música y representaciones sociales de la sexualidad: un estudio de caso sobre los jóvenes reggaetoneros en el Distrito Federal. (Tesis doctoral). Recuperada de http://zaloamati.azc.uam.mx/handle/11191/5647

[21] Cerbino, M., Chiriboga, C., \& Tutevén, C. (2001). La música en la constitución de las culturas juveniles. Culturas Juveniles. Cuerpo, música, sociabilidad y género (pp. 77-100). Guayaquil, Ecuador: Ediciones Abya-Yala. 
[22] Penagos, Y. (2012). Lenguajes del poder. La música reggaetón y su influencia en el estilo de vida de los estudiantes. Plumilla Educativa, 10(2). 290-305.

[23] Urdaneta, M. (2010). El reggaetón, invitación al sexo. Análisis Lingüístico. Temas de Comunicación, 20(1), 141-160.

[24] Díaz, R. (2018). El género musical reggaetón. Aproximación al discurso sexual y a la cosificación de las jóvenes. Experiencias pedagógicas e innovación educativa. 3683-3695. Recuperado de: https://www.researchgate.net/publication/333117957_El_genero_musi cal_reggaeton_aproximacion_al_discurso_sexual_y a la cosificacion de las jovenes.

[25] Green, I. E. (05 de 2019). Creative Trace: Tennessee Research and Creative Exchange Exchange. Recuperado el 21 de 04 de 2020, de Creative Trace: Tennessee Research and Creative Exchange Exchange https://trace.tennessee.edu/cgi $/$ viewcontent.cgi $?$ article $=6871 \&$ context= utk_gradthes

[26] Martínez, D. A. (2014). Música, imagen y sexualidad: el reggaetón y las asimetrías de género. El cotidiano, 29(186), 63-67.

[27] Piedad, Q. C. (05 de 2011). Análisis del impacto de la música reggaetón del cantautor Daddy Yankee y la influencia que tiene en la forma de actuar y relacionarse en las adolescentes del Instituto Femenino Victoria Vásconez Cuvi, segundo año de bachillerato de la especialidad de ciencias sociales, año lectivo septiembre 2010-junio 2011. Repositorio Digital Universidad Técnica de Cotopaxi. Recuperado el 21 de 04 de 2020, de Repositorio Digital Universidad Técnica de Cotopaxi: http://repositorio.utc.edu.ec/bitstream/27000/206/1/T-UTC-0234.pdf

[28] Bourdieu, P. (2002). Campo de poder, campo intelectual. Buenos Aires: Montressori. 